\title{
Circular Supply Chains in Emerging Economies - A comparative study of packaging recovery ecosystems in China and Brazil
}

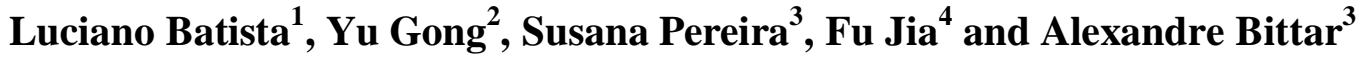 \\ ${ }^{1}$ Aston Business School, UK \\ ${ }^{2}$ Southampton Business School, UK \\ ${ }^{3}$ Escola de Administração de Empresas de São Paulo, Brazil \\ ${ }^{4}$ York Management School, UK
}

\begin{abstract}
This paper provides a circular supply chain perspective of packaging recovery ecosystems being implemented by Tetra Pak, a prime global player in the food packaging industry, in two major emerging economies: China and Brazil. The circular supply chain archetype considered in the research allowed a consistent comparative analysis of Tetra Pak's circular supply chains in both countries. Through a case study approach, the research provides theoretical propositions and learning points that are valuable for academics and practitioners interested in the Chinese and Brazilian markets as well as in the supply chains supporting recovery ecosystems in the packaging industry. In particular, the distinct environments in the Chinese and Brazilian markets render Tetra Pak opportunities to design circular supply chains in different ways showing adaptation and learning to local market characteristics. The industrial perspectives from these emerging economies add to the contributions offered in the paper. Overall, the conceptual considerations and practical recommendations presented in the paper provide useful insights for the development of further studies and implementation of industrial practices advocated by the circular economy.
\end{abstract}

Keywords: circular supply chains; packaging recovery ecosystems; circular economy; emerging economies; multinational operations

\section{Introduction}

As a response to climate change regulations, the rising costs of raw material acquisition and the environmental impact of disposal processes, over the last decade organisations have been systematically implementing production and supply chain systems to extend the life cycle of products, by-products and useful waste outputs (Lovins and Braungart 2014). Such operational capability represents a key principle of the circular economy, which advocates production systems that are restorative and regenerative by purpose, shifting production value chains from linear ('take-make-use-dispose') to circular ('take-make-use-recover') cycles (Webster 2015).

The transition to a circular economy predicated on production systems that take into account opportunities for reverse cycles (closed-loops) and cascading (open-loops) of products, by-products and waste outputs posits a crucial importance on the role that supply chains can play to enable circular flows involving the recovery of materials (Dervojeda et al. 2014; EM Foundation 2014; Howard, Hopkinson, and Miemczyk 2018). The implementation of such circular flows comprising closed- and open-loops of main products and waste materials increases the complexity and expands the scope of supply chain operations in the circular economy context (Govindan and Hasanagic 2018). Following the call for more integrative approaches to design sustainable supply chains (Bals and Tate 2018), the design of supply chains for the circular economy should take into account a holistic perspective integrating the different types of circular flows enabling the recovery of materials.

The circular flow of materials in the circular economy is often associated with restorative and/or regenerative processes that usually involve additional or alternative supply chains 
comprising actors from diverse sectors that play an important role in the materials recovery ecosystems they are part of (Pan et al., 2015; Batista et al., 2016; Zhu et al., 2010). In this context, the packaging industry is an important economic sector that has high priority in the circular economy agenda (EM Foundation 2012; EU Commission 2015). Packaging is an important element of finished products, playing a crucial role in the safety and preservation of food and beverage for example (Golini et al. 2017). Most one-way packaging, i.e. packaging produced for a single use, is discarded after use and it usually enters the waste stream after a period of less than a year (Hopewell et al., 2009). When it is not recovered for recycling, it is often associated as a symbol of unsustainable consumption and environmental degradation provoked by the industry (Hage and Söderholm 2008). Shifting from linear flows of packaging to circular flows as encouraged by the circular economy is therefore critical for the sustainability performance and reputation of the packaging industry.

Over the years, companies in the food and beverage packaging sector have pioneered a number of initiatives to implement packaging recovery and recycling ecosystems as part of their circular economy strategies (Niero et al., 2017). Many initiatives in the sector are led by large multinational corporations such as Tetra Pak, which operates in several emerging economies where a high proportion of packaging often ends up in landfill due to limited waste management infrastructure (Sheriff et al., 2017). An added complexity to design and implement the circular supply chains necessary to support recovery processes for packaging waste in these economies is the varied configuration of stakeholders that play crucial roles in packaging recovery ecosystems (Coelho et al., 2011; Zhang and Wen 2014).

Despite the growing recognition of the benefits promoted by material recovery initiatives in the circular economy and their potential to drive fully sustainable production ecosystems (Preston 2012), little is currently understood about the circular supply chain models supporting packaging recovery practices across different markets and their replicability in different emerging economies around the world. In addition, the clear characterisation of what constitutes a 'circular supply chain' in relation to the closed- and open-loops involved, the practical implementation of supply chain process circularities, and the wider configuration of the network of actors enabling materials recovery processes are issues that still remain to be holistically addressed in further empirical studies.

This paper reports the outcomes of an empirical study that addresses the issues above mentioned by applying a conceptual circular supply chain framework to analyse packaging recovery ecosystems in distinct emerging economy contexts with substantial volume of packaging waste, such as China and Brazil. Accordingly, the following research questions are specified for the study:

1. What distinctive circular supply chain model can capture the wide range of material recovery flows in circular economy business ecosystems in China and Brazil? What are the differences and similarities?

2. How do global packaging producers design circular supply chains in order to address waste problems in the sector?

To answer these questions, we develop a conceptual model of a circular supply chain depicting the different materials recovery loops it may involve. The model allows a comparative analysis of packaging recovery ecosystems being implemented by Tetra Pak, a premier provider of food packaging with operations in several countries worldwide, including Brazil and China.

These two countries in particular have very large populations and geographical areas. For instance, China has the first and Brazil the fifth largest populations in the world, and in terms of area China and Brazil are respectively the fourth and fifth largest countries in the world 
(United Nations Statistics Division - unstats.un.org). The logistics operations of food distribution systems in these countries involve substantial transportation of food through distances similar to continental dimensions. The aseptic packages developed by Tetra Pak comprise a unique combination of paperboard, aluminium and polyethylene that allows distribution and storage of beverages without refrigeration for long periods of time. This capability brought immense benefits for the logistics of perishable products and it was particularly welcomed in China and Brazil, where the food sector generates substantial demand for Tetra Park products. Due to their widespread use, Tetra Pak products contribute to a significant proportion of packaging waste in those countries. This represents a concerning issue for the adoption of circular economy practices in Brazil and more particularly in China, whose government has officially acknowledged the circular economy as a central sustainable development strategy and its successful enforcement is seen as a way for China to tackle its urgent problems of environmental degradation and resources scarcity (Su et al. 2013; Jia et al. 2018).

China and Brazil also have peculiar market and social characteristics that bring specific challenges and opportunities to the implementation of packaging recovery ecosystems and related circular supply chains. The unique regional and industrial characteristics considered in this study provides a compelling setting for analysis from which we derive pioneering perspectives and relevant insights that shed light on the operationalisation of circular supply chains that support the adoption of the circular economy praxis by organisations.

The remainder of this paper is organised as follows. In the next section we provide the theoretical basis of a circular supply chain model that takes into account typical materials recovery processes advocated by the circular economy. The framework provides the conceptual reference to support a comparative analysis of packaging recovery ecosystems being implemented in China and Brazil. This is followed by the presentation of the research methodology adopted in the study. The research findings are presented in the sequence, including a detailed explanation of the circular supply chains supporting packaging recovery ecosystems developed by Tetra Pak in China and Brazil. The discussion section that follows addresses similarities and differences between both countries and offers relevant propositions derived from the research findings. The paper is concluded by addressing research limitations and pointing out suggestions for future research.

\section{Recovery flows and circular supply chains}

In order to develop a comparative analysis of circular supply chains supporting packaging recovery ecosystems in two distinct regions, it is important to establish the conceptual reference against which comparisons can be made on a coherent and structured way. It is also our intention to position the analysis in the circular economy context. Accordingly, before considering waste issues faced by the packaging industry and general waste recovery processes developed in the sector, we provide a theoretical characterisation of materials recovery flows encouraged by the circular economy and the conceptual aspects of a circular supply chain archetype representing such flows.

\subsection{Circular economy aspects}

A growing body of literature is establishing the philosophical paradigms of the circular economy, developing the theoretical and practical foundations that place 'triple bottom line' sustainability and prolonged use of resources as inherent aspects of production systems (Lovins and Braungart 2014). As a matter of fact, these philosophical paradigms are not new. They have been considered decades ago through the pioneering works of Elkington (1998) and Giarini and Stahel (1989). For example, in the late 90s Elkington (1998) proposed the 
'triple bottom line' concept by drawing businesses' attention to the importance of placing the three inter-linked goals of economic prosperity, environmental protection and social equity at the top of their corporate agenda. These three goals represent the fundamental dimensions of sustainability and they drive the market logic for businesses and supply chain operations aimed at maximising societal and environmental benefits without detriment to economic benefits (Lacy and Rutqvist 2015; Preston 2012).

By their turn, Giarini and Stahel (1989) argued that economic growth should integrate economic and ecological factors and the notion of resources 'utilisation' should be based upon waste prevention and extended use of goods. The maximisation of resources utilisation is a core tenet of the circular economy and it is reflected in the definition proposed by Webster (2015, p.16), who defines circular economy as a sustainable economy "that is restorative by design, and which aims to keep products, components and materials at their highest utility and value, at all times".

The contemporary view of the circular economy has evolved to incorporate a variety of industrial practices based on the circular flow of materials that can be used in multiple production instances (Geissdoerfer et al. 2017). Such practices are based upon waste minimisation and increased product utilisation at post-use stages that are typical of $6 \mathrm{R}$ approaches, e.g. reduce, redesign, reuse, repair, recycle and remanufacture (Badurdeen et al. 2009; Kuik, Nagalingam, and Amer 2011; EM Foundation 2012; EM Foundation 2014; O'Connor et al. 2016).

Business innovations to implement 6R can be achieved through the purposeful design of materials recovery processes and related circular supply chains (Dervojeda et al., 2014; Lovins and Braungart 2014; De Angelis et al., 2017; Murray et al., 2017). In essence this is grounded on the fundamental principle that a circular economy is restorative and regenerative by intention and design (EM Foundation 2012).

\subsection{A 'circular' supply chain archetype}

The integration of sustainability principles into supply chain management is a key issue concerning corporate competitiveness in the current socio-economic-environmental context (Brandenburg and Rebs 2015). It is important to recognise that the implementation of materials recovery processes within and between organisations brings an increased complexity to the design of the supply chains they involve (Akturk, Abbey, and Geismar 2017; Jabbarzadeh, Fahimnia, and Sabouhi 2018). For instance, the circular cycles in materials recovery value chains are enabled by supply chains that implement material flows from consumption points to production points. This is typical of reverse logistics approaches. However, reverse flows do not necessarily represent all cases of circular (loop) flows that can be implemented in a circular supply chain, as the loop flows may not involve returns to the focal company. Despite enabling reverse flows, we argue that the reverse supply chain perspective is insufficient to address the wide scope of recovery processes and related supply chain configurations that occur in the circular economy. For instance, circular flows can also be implemented through processes involving the forward feeding of products, by-products and waste materials into further production process of other companies (Leigh and Li 2015).

From the aspects above mentioned, it follows that in the wider perspective of the circular economy the material flows in a circular supply chain may comprise reverse (closed-loop) flows as well as forward (open-loop) flows of materials. For example, materials recovery processes may comprise closed-loop flows which refer to reverse flows involving organisations within the supply chain of a focal company (Govindan and Soleimani 2017). Additional flows may involve cascading processes through forward flows (i.e. open-loop flows) of materials into other supply chains linking further organisations implementing waste 
or by-product synergies (Cimren et al., 2011). For Govindan et al. (2017), to enhance the financial and ecological performance of the supply network, the forward and reverse flows must be designed to integrate well so that decisions taken in both areas complement each other.

From a holistic angle, it can be argued that the extended scope of a circular supply chain encompasses all supply chain loops (closed and open) enabling recovery flows of a sustainable business ecosystem (Batista et al. 2018; De Angelis, Howard, and Miemczyk 2018).

Although the literature indicates academic research with direct references to 'circular' (or the idea of circularity) in supply chains (Genovese et al. 2017; Nasir et al. 2017), its characterisation still remains a marginal venture in the field of operations and supply chain management (Batista et al. 2018). There is a lack of conceptualisation on what constitutes a 'circular supply chain' in the context of a circular economy ideal.

Over the years a growing number of studies concerned with the sustainability of supply chains has created a substantial body of literature in which four sustainability narratives of supply chains have emerged, namely: reverse logistics, green supply chains, sustainable supply chain management (SSCM) and more recently, closed-loop supply chains.

It is possible to associate these narratives with specific emphases regarding the notion of 'circularity' in supply chain operations research. For instance, Govindan and Soleimani (2017), Jalil et al. (2016) and Govindan et al. (2015) point out that reverse logistics is usually associated with supply chains that enable products to flow back into corporate operations, minimising the flows to landfill waste. Green supply chain research can be particularly related to a strong emphasis on reducing environmental and ecological impacts through product/process design and materials recovery (Mishra et al., 2012; Dües et al., 2013). Sustainable supply chain management (SSCM) engages with broader corporate governance and strategic management of supply chains enabling more sustainable operations and related material flows (Fabbe-Costes et al., 2014; Zorzini et al., 2015; Beske and Seuring 2014). Finally, closed-loop supply chains are associated with restorative supply chain models that include reprocessing of end-of-life products and parts, as well as integration of forward and reverse supply chains to cover entire product life cycles from cradle to grave (Krikke et al., 2004; Guide and Van Wassenhove 2009; Das and Posinasetti 2015; Cannella et al., 2016).

Although these four narratives can be related to particular circular flows that are relevant to the circular economy, none of them addresses the full spectrum of circular flows of products, by-products and waste encouraged by the circular economy. From the four narratives above considered, the closed-loop supply chain narrative is the one that considers a wider range of circular flows implemented by circular economy business models. Yet, we argue that the closed-loop supply chain narrative is still not sufficient to address the full scope of post-production and stewardship operations espoused by the circular economy, such as for example the supply chain operations supporting waste flows and by-product synergies linking organisations across diverse sectors. The closed-loop narrative tends to focus more on the flows of products to the detriment of waste and by-products flows, as implied by Guide and Van Wassenhove (2009), who point out that closed-loop supply chains focus on value creation systems derived from 'product' life cycles and related returns.

This calls for a sustainable supply chain perspective that provides a more comprehensive conceptual basis to support the design of broader industrial ecosystems involving different loops of products, by-products and waste. Indeed, previous studies have drawn attention to the narrow scope of the environmental aspects considered in the design of sustainable supply chains (Eskandarpour et al. 2015). We address this gap by presenting a circular supply 
chain model which builds upon and expands the closed-loop supply chain perspective. To this end, we assume that the circular supply chain perspective represents an expansion of the closed-loop supply chain perspective in terms of scope and focus of the materials recovery systems considered. More specifically, in terms of scope circular supply chains extend the boundaries of closed-loop supply chains by taking into account post-production stewardship to include forward feeding flows (open loops) into alternative supply chains. In terms of focus, circular supply chains support sustainable value chain systems derived not only from end of life returns, but also from associated by-product synergies and waste recovery flows.

In this sense, circular supply chains consist of a supply network of organisations implementing provision and recovery flows of materials, by-products or waste. Such circular flows may comprise a myriad of recovery streams as illustrated in Figure 1, which provides an archetypal representation of a supply chain involving all types of materials recovery flows.

More specifically, the supply chain archetype shown in Figure 1 points out distinct material recovery flows inherent in circular supply chains. The model points out a number of circular flows that vary in terms of direction (closed or open loops), scope (short or long loops) and materials involved. Examples of 6R initiatives that can be potentially implemented through diverse loop flows in the supply chain are also shown in the figure.

Figure 1. A circular supply chain archetype (adapted from Batista et al. [2018])

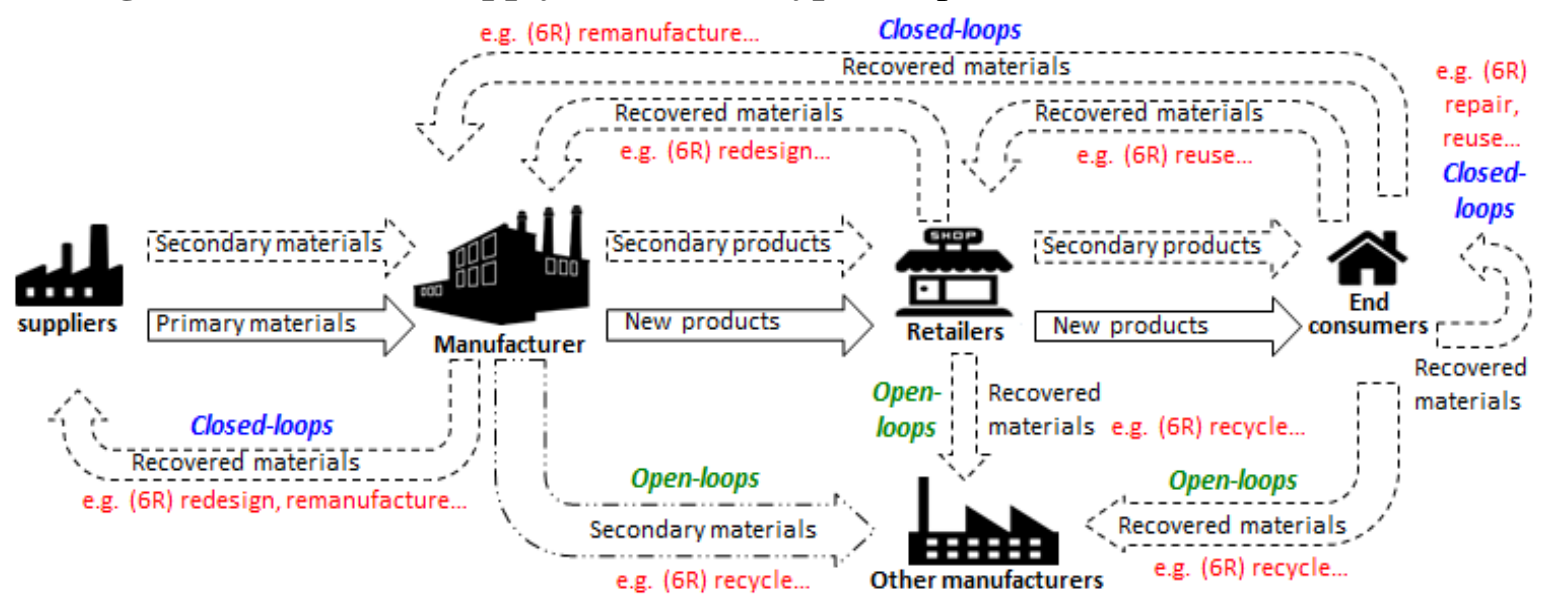

For Fahimnia et al. (2017), truly sustainable organisations assign strategic importance to how their supply chains are designed and managed. The implementation of different loops in a circular supply chain usually requires the involvement of several actors across the supply chain. The purposeful design of the integrations and relationships between key stakeholders in the supply chain determines the structure and efficiency of the supply chain (Zeng et al. 2017; Calleja et al. 2018).

The complex universe of stakeholders that may get involved in a circular supply chain requires the development of orchestrated collaborations comprising specific buyer-supplier relationships necessary to enable different recovery flows. The leadership role of the focal firm in this context is a crucial factor for the development of the supply chain.

Early researchers (Stevens 1989; Cooper et al. 1997) have acknowledged that leadership is a key component of supply chain management. Lambert et al. (1998) pointed out that unless one organisation takes the leadership role for strategic supply chain decisions and collaborations, risks will occur throughout the chain and lead to chaos.

Over the years the supply chain literature embraced a dearth of publications and empirical studies devoted to leadership in the supply chain domain (Harland et al. 2007; 
Overstreet et al. 2013). More recently, Gosling et al. (2016) propose that leadership can facilitate higher level collaborations among suppliers, which leads to supply chain innovations, including sustainability oriented initiatives. This matter is further investigated by Gong et al. (2018), who studied supply chain leadership roles in orchestrating supply chain collaborations on three multi-tier sustainable supply chain projects in China.

Acknowledging the critical importance of leadership in supply chain management, we add to the substantial body of literature further insights on the topic by taking into account the leadership role played by a focal firm implementing circular supply chains.

\section{Methodology}

The research involved a comparative study of packaging recovery ecosystems being implemented in two emerging economies, China and Brazil specifically. A case study approach was applied to capture the particular features of packaging recovery chains developed by Tetra Pak, a key supplier of packaging products for the food and beverages industry with widespread operations in both countries. In methodological terms, the subject case was therefore Tetra Pak and the unit of analysis was the company's circular supply chain enabling packaging recovery processes being implemented in two particular regional contexts, namely: China and Brazil.

Specifically, the research involved a case study approach in which qualitative research methods were applied to derive insights from specific packaging recovery supply chain ecosystems, including structures, processes, stakeholders, contextual factors and interactions linking provider-customer dyads across the supply chains analyzed.

In conformity with qualitative research approaches (Bryman and Bell, 2015), we employed a variety of techniques such as observation, examination of texts and documents, conduction of interviews and related recording/transcribing processes to extract data for the purpose of understanding and analysis. The logic behind applying a qualitative approach was to achieve an in-depth understanding of the dynamics arising from the circular supply chain ecosystems (the phenomenon in question) and related operational and managerial processes taking place in particular markets.

The subject case (Tetra Pak) and particular regional contexts (China and Brazil) were selected following a purposive sampling strategy, which is a nonprobability sampling method where sample is selected with basis on the characteristics of a population and the objective of the study (Yin 2013). According to Patton (2015), the logic and power of purposive sampling is based on the selection of information-rich cases of central importance to the purpose of the inquiry, as they provide the subjects, contexts and circumstances that are of particular interest to the research and from which relevant insights can be generated to support in-depth understanding. A particular case is considered information-rich when it provides excellent or strong examples where the phenomenon of interest manifests sufficient intensity to support comprehensive understanding.

Accordingly, Tetra Pak and the packaging recovery ecosystems the company is implementing in China and Brazil were purposefully targeted in this study because they featured relevant models of circular supply chain implementation initiatives advocated by the circular economy. Moreover, the large scope of Tetra Pak packaging production and recovery operations in China and Brazil provided a timely phenomenal opportunity for scientific investigation of the subject in the context of two major emerging economies where the scale and the complexity of the operations and supply chain structures provided suitable information-rich scenarios and intensity of examples to support comprehensive analysis and understanding.

In the study, the main method applied for primary data collection was semi-structured 
interviews conducted with managers from provider and customer organisations from key stakeholders involved in Tetra Pak packaging recovery ecosystems in China and Brazil. A total of 21 managers from Tetra Pak and key related supply chain actors were interviewed, 11 from China and 10 from Brazil. The interviews were conducted in China and Brazil by members of the research team who are native speakers of Mandarin and Brazilian Portuguese, which increased the reliability of the research processes involving data collection and translation. All members in the research team members are fluent in English in addition to their mother, which allowed the adoption of English as the common language for interpretation and analysis of the data by the group as a whole.

Besides the interviews, visits were also paid to key operations in the circular supply chains in both countries. For instance, the case study in China included visits to Tetra Pak's main operations in Shanghai as well as visits to main packaging recycling plants which have the operational and specific technological capabilities to recycle Tetra Pak packaging (e.g. separation of paperboard, aluminium and polyethylene layers). The case study in Brazil included visits to Tetra Pak's main operations in São Paulo State and visits to packaging recycling organisations, a waste collection cooperative, an association of organisations in the packaging sector and a government environmental agency. Tables 3 and 4 in the Appendix present the composition of the overall group of managers interviewed in the visited sites in China and Brazil respectively.

The selection of managers followed the purposive sampling strategy adopted in the study. Thus, participants were selected from key departments involved in core operations and supply chain activities of packaging recovery ecosystems. They were also highly knowledgeable managers with decision making power to establish and maintain relationships with key stakeholders.

The interviews were conducted over the period of September 2014 and July 2016 for China and one year starting mid-2016 for Brazil and they involved face-to-face sessions that lasted between 60 to 120 minutes on average. The interviews were audio-recorded and subsequently transcribed and coded with the support of the software QSR NVivo 10. The themes developed in the interviews referred to the operational implementation of packaging recovery flows, the role played by key stakeholders in the recovery ecosystem and the related interconnections between the organisations involved.

Guba's credibility qualities of trustworthiness in qualitative research (Guba 1981) were observed in the study, including (1) trackable variability was ascribed to sources in which variability stem from the range of experience rather than the average experience; (2) data was collected from, and peer examined by, persons who are familiar with the phenomenon being studied; and (3) triangulation of data source also involved persistent observation on service sites. As suggested by Lincoln and Guba (1985), the investigators were responsive and conscious of contextual circumstances, with professional immediacy, sensitivity and ability for clarification and summarization of the data collected.

To facilitate understanding of the complex packaging recovery ecosystems being studied, the circular supply chain archetype describe in Section 2 provided the theoretical framework for identification key Tetra Pak packaging recovery processes being implemented in China and Brazil, including characterisation of the recovery flows in terms of level and scope, the supply chain configuration, i.e. network of actors, the role of main stakeholders and the sustainability capabilities achieved by the recovery ecosystem as a whole.

Indeed, the circular supply chain archetype helped to depict the structure of packaging recovery ecosystems in a holistic way, including main operations and supply chain elements as well as the interconnections between providers and customers. The framework was instrumental in making key ecosystems' structures and links visible and comparable across 
the different countries considered in the study. In this context, the wider perspective of business ecosystems as suggested by Moore (2006) was considered. From this perspective, a business ecosystem is seen as an 'economic community' supported by an arrangement of interacting organisations comprising lead producers, customers and other key stakeholders such as community associations, financing and trade associations, labour unions, NGOs and government institutions.

\section{Research findings}

Tetra Pak is a large multinational food packaging manufacturing firm of Swedish origin, with operations in several countries around the world and employing thousands of employees globally. The company offers a wide range of packaging solutions for dairy products, juices and processed food. Tetra Pak's commitment with sustainability is publicly conveyed in its corporate vision, which states that the company "...believe in responsible industry leadership, creating profitable growth in harmony with environmental sustainability and good corporate citizenship." (www.tetrapak.com/about/vision-and-mission).

The implementation of environmentally sustainable practices through the recovery of used Tetra Pak packaging across its many operations worldwide represents a major challenge for the company. Due to the complex multi-layered composition of paperboard, aluminium and polyethylene materials in its packaging, and food regulation requirements, Tetra Pak cannot produce packaging from recycled materials. Therefore, the company's main supply chain of packaging products is still based on the traditional linear system that implements the standardised 'take-make-use-dispose' value chain processes shown in Figure 2 across all its operations around the world. This represents the central forward flows in the circular supply chain archetype shown in Figure 1. Tetra Pak replicates this part of its supply chain in China (Figure 3) and Brazil (Figure 4).

\section{Figure 2. Tetra Pak linear supply chain}

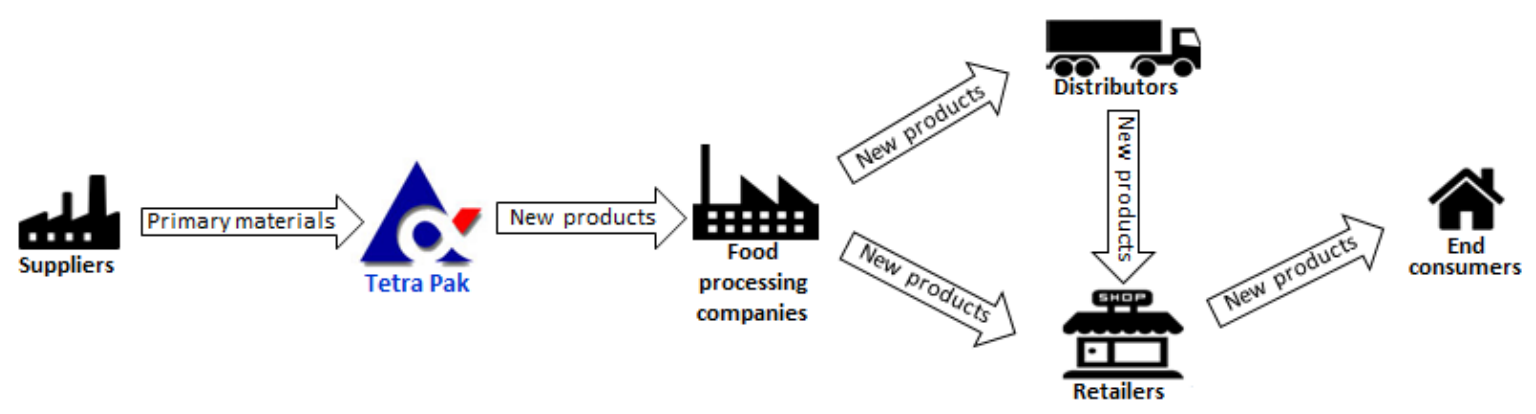

To operationalise its packaging recovery flows, Tetra Pak has to implement circular supply chains to support recovery processes supporting cascading flows of used packaging into recycling operations that are able to derive a number of materials that are used as feedstock by manufacturers of different recycled products. Such circular supply chains rely on a number of third party organisations and other stakeholders that present a varying ecosystem configuration across different countries, as evidenced by the findings of the specific cases studies discussed next.

\subsection{Tetra Pak's packaging recovery ecosystem in China}

Tetra Pak began its operations in China in 1979 and it currently employs over 2,000 employees. The company brought the ultra-heat treatment (UHT) technology to China, which together with the aseptic packaging technology made it possible to distribute milk from the 
major northern production provinces to the southern consuming provinces. Concentrating on UHT milk in the Chinese market, Tetra Pak expanded successfully along with booming dairy consumptions. The company consolidated its position as a major player in the Chinese food packaging sector, achieving a large proportion of local market share. Due to competition Tetra Pak's market share in China is currently down. The company however is still a major provider of packaging in the Chinese market.

In consonance with the corporate vision, Tetra Pak China seeks to emphasise sustainability in its operations. In 1998, the company set up its Environmental Department to look into the recycling issue concerning Tetra Pak packaging, which the company technically terms as UBC (used beverage cartons). After investing over 150 million RMB (21.7 million USD) over a period of ten years, Tetra Pak China's circular supply chain supporting recycling operations took shape in 2009.

With basis on the circular supply chain model presented in Figure 1, we depict in Figure 3 the circular supply chain of Tetra Pak China. The figure shows that the company does not supply secondary products produced from secondary materials. The central 'linear' forward processes in its supply chain comprise only new products based on primary materials. The supplier base for these processes involves a multi-tier structure of suppliers of paperboard, polyethylene and aluminium. Tetra Pak China has to import complementary proportions of these primary materials from external markets in order to fulfil the company's demand of raw materials.

Figure 3. Tetra Pak's circular supply chain in China

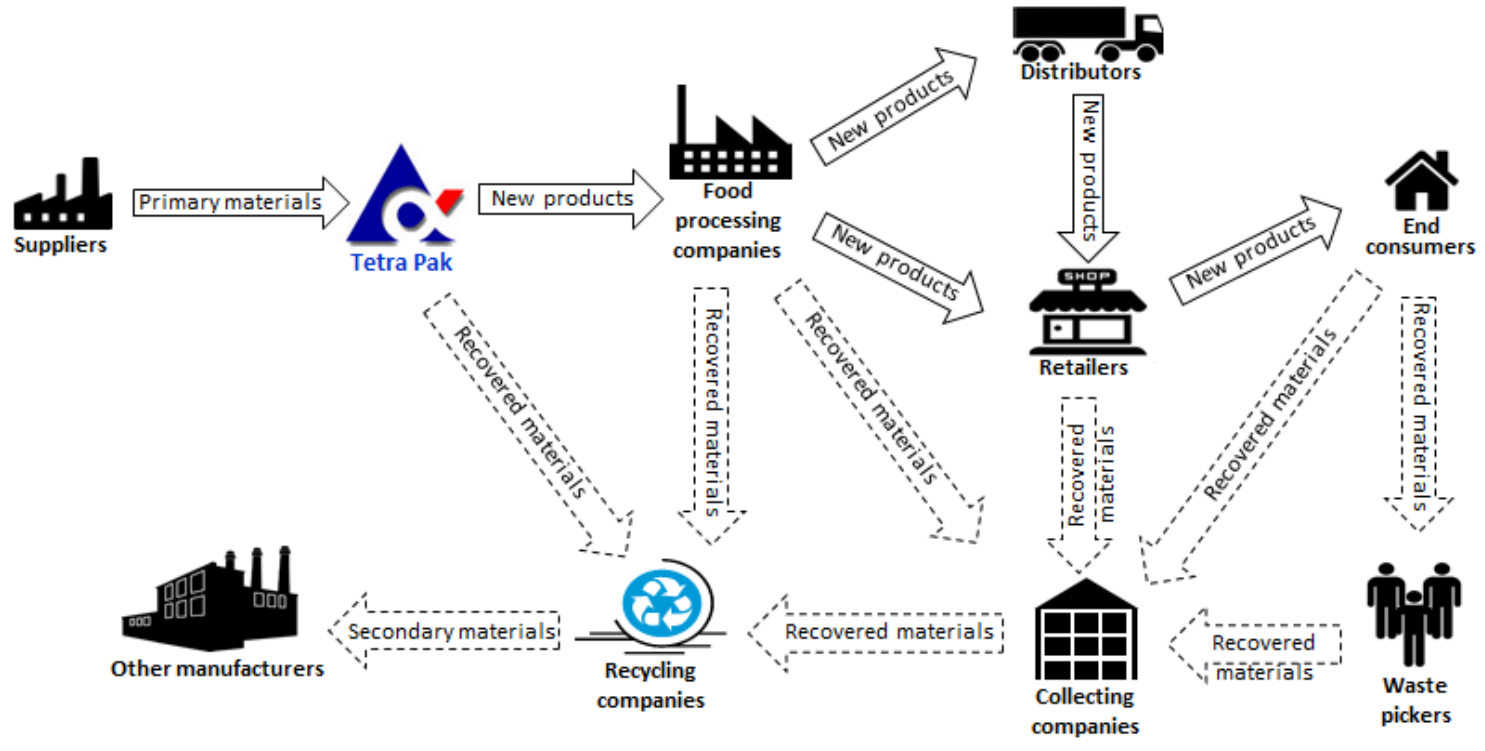

As shown in Figure 3, Tetra Pak's circular supply chain in China is mainly comprised by open-loops. These recovery flows include eight SME recycling companies with annual processing capacity varying between 20,000 and 40,000 tons. They receive disposed packaging from production errors at Tetra Pak and food processing companies. The substantial volume of recovered packaging however comes from small collection centres, which play the important role of hub channels concentrating the flows of UBCs from a wide number of retailers, end consumers and waste pickers. From these sources, individual waste pickers represent the major force that collects UBCs for the collecting companies. Despite being an informal structure, they manage to efficiently provide materials to these companies. 
Starting from zero UBC recycling processes, in 2015 the packaging recovery ecosystem created by Tetra Pak China achieved a recycling rate of $28 \%$. Tetra Pak China played a critical role in shaping its circular supply chain over time. The implementation process required close relationships with key stakeholders in the ecosystem, as discussed next.

\subsubsection{Recyclers' role in the circular supply chain}

As Tetra Pak does not recycle UBCs itself, the recycling companies play a crucial role in the company's circular supply chain. In China, thus far Tetra Pak developed collaborations with eight small and medium recyclers in order to increase the recycling capacity for its UBCs. The recyclers are able to transform the UBCs into useful second materials that supply a secondary market. For instance, in China the recyclers apply two main types of technology to process UBCs. One type processes UBCs into separate commodities such as paper, polyethylene and aluminium respectively. The other processes UBCs as a whole, generating secondary raw materials that serve as feedstock for other manufacturers to produce different types of recycled packaging or recycled fences, furniture, etc.

As $75 \%$ of the UBC is made of a long fibre material which has high quality to produce recycled paper several times, Tetra Pak China proactively approached paper mills companies and persuaded some of them to engage with the circular supply chain. Tetra Pak also provided several supporting initiatives to develop the recyclers' capability to process the UBCs. For instance, Tetra Pak: (1) Invested in recycling equipment which was provided to the recyclers for free; (2) Provided recycling companies with discounted packaging waste materials from its manufacturing operations; (3) Provided management training to recyclers to enhance their managerial skills; (4) Organised an annual recycling conference where recyclers could exchange experiences and be informed about industry trends and latest advanced technologies; and (5) Helped recyclers to upgrade their recycling technology in order to enhance the recycling value, which increased collection processes.

An interesting example of a specific initiative to promote technological upgrade was Tetra Pak collaboration with a local university and entrepreneur to develop the technology to separate polyethylene and aluminium, a combination termed "PolyAl", from Tetra Pak's UBCs. The new technology was installed in 2009 in one of the supply chain recyclers. The success of the initiative is evidenced by the following comment from the managing director:

"After we implemented the PolyAl separation line, the value of the UBCs has increased by 30 per cent and our monthly sales increased by 25 per cent." (Managing Director)

Overall, with the support from Tetra Pak the recyclers' capacity to recycle UBCs was significantly improved to the extent that some recyclers are exclusively dedicated to recycle UBCs. These recyclers developed their own recycling channels, which helped to consolidate the UBC recycling network over time.

\subsubsection{Collaboration with collectors and waste pickers}

The network of collectors and individual waste workers represent a major work force to collect recyclable materials in China. Linzner and Salhofer (2014) estimate that approximately 3.3-5.6 million people are involved in informal waste collection activities in urban China. When Tetra Pak started building its circular supply chain, the company was aware of this workforce and the important role they could play in collecting UBCs for the recycling companies. The company therefore sought to develop collaboration and supporting mechanisms for waste pickers and middle collectors.

The fact that UBCs could be recycled needed to be communicated to collectors and 
waste pickers. Tetra Pak has therefore engaged with this network to let them know that UBCs could be recycled and there was demand for it from the recycling companies which were supporting. One example involves collaboration between Tetra Pak and a collecting company. For instance, the majority of waste pickers in China have limited education, which makes it ineffective to communicate with them via written materials such as posters. At the end of 2006, Tetra Pak partnered with the earliest collecting company in Beijing to purchase UBCs from waste pickers and organised a training event to develop waste pickers' awareness of the value of UBCs. More than 100 people attended this event. In 2007, they held two more similar events, which attracted participants from more than one hundred local communities in Beijing.

Tetra Pak also provided free balers to collectors in order to help them transport the UBCs to the recyclers in a more organised and cost effective manner. In 2009, Tetra Pak together with some collectors launched the 'pick-king' campaign, which awarded outstanding waste pickers for picking the highest volume of UBCs in a given period. This helped to increase the flow of recovered materials in the circular supply chain.

\subsubsection{Engaging with end consumers}

Tetra Pak launched a series of campaigns targeting the public in order to educate consumers on environmental protection and developing awareness on the fact that UBCs can be recycled into useful raw materials for other manufacturers.

For example, in May 2005 Tetra Pak and the newspaper Shanghai Youth Daily held a large communications campaign for two months emphasizing the theme "Recycle Tetra Pak UBCs, happy for environmental protection." From 2007, Tetra Pak launched recycling education programs with the slogan "Green life, start from me" for three consecutive years in several primary schools in Beijing. In May 2008, Tetra Pak donated hundreds of benches made from approximately 120,000 UBCs to the Beijing's Olympic Forest Park. In 2009, Tetra Pak launched another campaign, "Green World Expo, proud of me," to support the Shanghai World Expo. Approximately 700,000 people took part in this campaign, which covered the local communities in 12 districts in Shanghai. Over six months after this event, 113 tons of UBCs were collected and recycled in the region.

\subsubsection{Engaging with business customers and retailers}

The public campaigns developed by Tetra Pak China also had a strong influence on the company's business customers (food processing companies) and retailers. The company sought to engage actively with these two important stakeholders in order to reinforce awareness and the flow of recovered UBCs to sustain its circular supply chain.

For example, in the month following the Shanghai Expo previously mentioned, several retailers and customers of Tetra Pak invited the company to give presentations on environmental protection and provide them with ideas for their own waste recycling. Among these companies, Mengniu Dairy (leader dairy processor in China in terms of sales revenue) was the first company in China to implement the idea of 'paid packaging recycling'. To this end, Mengniu placed UBCs collecting machines in a number of supermarkets across the country. End consumers were rewarded after they input a certain amount of packaging material in the machines. This was however a one-off initiative that was not replicated by other retailers, i.e. it did not scale up to represent a circular supply chain feature.

\subsubsection{Main challenges faced by Tetra Pak China}

As Tetra Pak's packaging recovery ecosystem developed over time, the company witnessed a steady increase of the recycling rate for UBCs. However, the company had to absorb most of 
the costs associated with the initiatives to establish its circular supply chain. The cost to keep a continuous increase of the recycling rate is still a major challenge for Tetra Pak.

Another challenge hindering the increase of the recycling rate relates to the fact that China does not have an established classification system for waste disposal and collection. Although consumers have been developing an increased awareness that UBCs can be recycled, they have not developed the habit of selective disposal of garbage due to the lack of reinforcing legislation and education on what concerns selective disposal. Thus, a substantial amount of UBCs still ends up in landfill or incinerations.

Moreover, the collection channels for UBCs rely on informal networks of waste pickers and this raises concerns on the dependability of such system. Furthermore, most of the collectors in the country are mainly small and medium enterprises (SMEs) with no professional managerial structure. The establishment of more formal collection systems, processes and networks is still in its infancy. The Chinese government proposition to modernise the informal waste collection system still remains to be translated into action. In fact, Tetra Pak China and recyclers lack support from wider legislation in the area.

Finally, the recycling price of UBCs fluctuates with the international price of paper. Low price of paper gets the value of UBCs down, which demotivates waste pickers to collect UBCs.

\subsection{Tetra Pak's packaging recovery ecosystem in Brazil}

Tetra Pak started its operations in Brazil in 1957 and it currently employs over 1,600 employees across its two packaging plants, one in Monte Mor (São Paulo State) and the other in Ponta Grossa (Paraná State). After China, Brazil is the second largest operations of Tetra Pak in the world in terms of sales volume.

During the 1990s, Tetra Pak Brazil started to implement a series of sustainability initiatives. The company invested in the adoption of certified raw materials for its production processes. One environmental achievement was to reach 100\% of FSC (Forest Stewardship Council) certified paper in 2008 in its production process. In 2016, the volume of packages with printed FSC logo reached 88\%, making Tetra Pak Brazil a world leader in the inclusion of FSC logo in the group as a result of its influence over its customers. Tetra Pak Brazil also began to invest in renewable raw materials to tackle waste issues. The company is a pioneer in the use of polyethylene derived from sugar cane for the production of the lids used in its packages. In 2014, the company substituted some of the polyethylene package layers by this green plastic, achieving a proportion of $82 \%$ of renewable raw materials in the composition of its packaging.

In parallel with the initiatives above, Tetra Pak Brazil started developing its circular supply chain to enable the recovery ecosystem for its UBCs. Currently, the main stakeholders involved in the circular supply chain are raw material suppliers, business customers, end consumers, waste collection service companies, waste collecting cooperatives and recyclers. Figure 4 shows a more detailed configuration of the company's circular supply chain. From a circular supply chain (Figure 1) perspective, we can see that similarly to the Chinese operations Tetra Pak Brazil does not supply secondary products produced from secondary materials. The central 'linear' forward processes in the Brazilian supply chain operations comprise only new products based on primary materials, which are supplied by three main suppliers. Paper is supplied by the largest national paper producer and exporter in Brazil, which has $100 \%$ of its products certified by FSC. This supplier is also a signatory of the UN Global Pact and the National Pact for Eradication of Slave Labour. Polyethylene is supplied by the world leader in the production of biopolymers, and aluminium is provided by a major multinational supplier of light metals. Differently from China, Tetra Pak Brazil is able to 
source $100 \%$ of its raw materials locally, without the need to import supplementary materials from external markets.

Figure 4. Tetra Pak's circular supply chain in Brazil

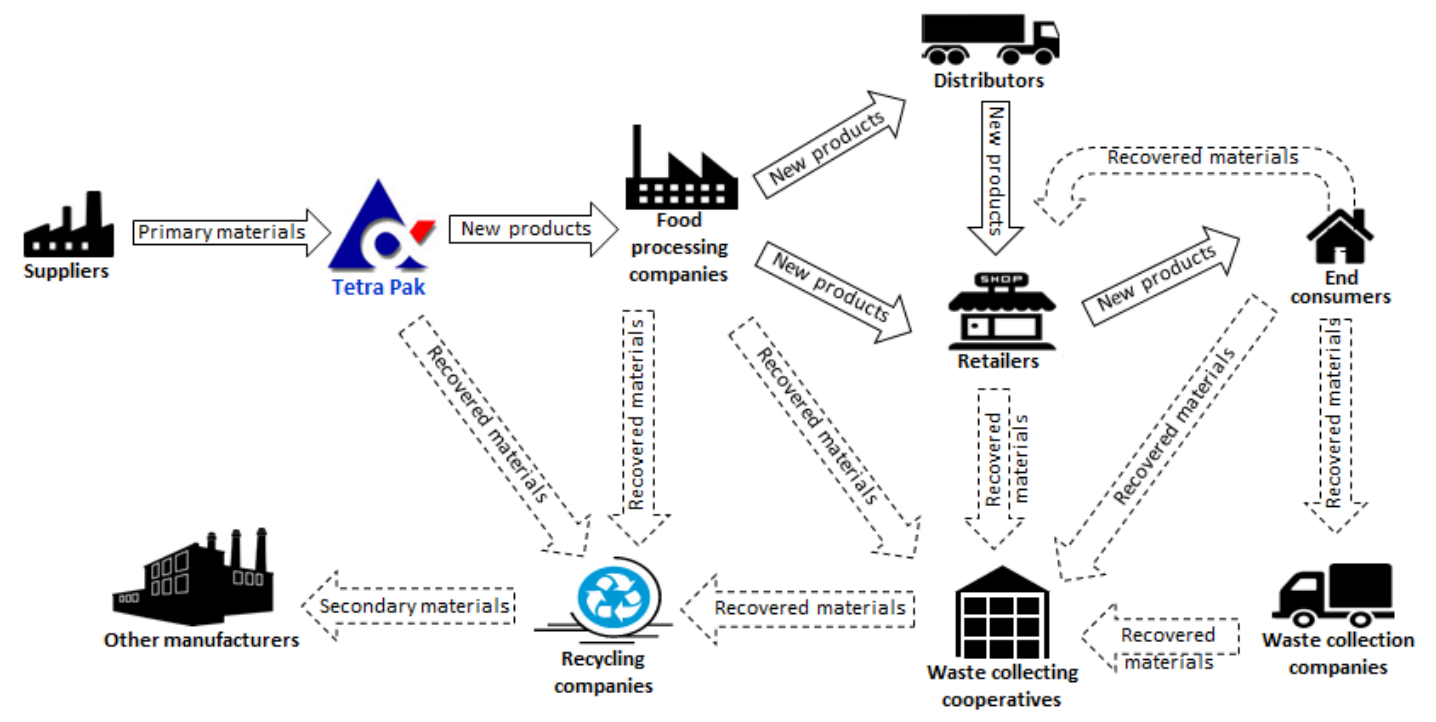

Based on the circular supply chain archetype presented in Figure 1, Figure 4 shows that the packaging recovery flows in the Brazilian supply chain are predominantly characterised by open-loop (cascading) flows. However, differently from the circular supply chain in China, one close-loop linking packaging returns from end consumers to retailers was identified. This is due to the retailers initiatives pointed out in Section 4.2.4 below.

More specifically, key stakeholders in the Brazilian supply chain are waste collection companies, cooperatives and recyclers, with end consumers and retailers also playing important roles. For example, although in a small scale, end consumers play an active role in the process by separating recyclable waste for public waste collection. They can also take recyclable packaging to recycling cooperatives or retailers' collection points.

The waste collection companies are service organisations contracted by local government (city councils) to perform public waste collection from end consumers. Through selective collection systems the recycled materials collected by these companies are made available to waste collecting cooperatives that separate the UBCs from other recyclable materials. The UBCs are then supplied to specific recycling companies in the chain. In 2016 the Tetra Pak's circular supply chain in Brazil achieved a recycling rate of $23.3 \%$, reaching more than 60,000 tons of recycled packaging.

\subsubsection{Recyclers' role in the circular supply chain}

Tetra Pak developed partnerships with paper recycling companies in Brazil, influencing them to enter in the business of recycling aseptic packages. This is illustrated by the following comment from one of the recyclers' managers: "...everything we do in the long-life package recycling we learned from Tetra Pak... even today, when we have a problem, we ask Tetra Pak to help us with the experience they have to increase efficiency". There are 14 recyclers that learned and developed the technology to separate the main Tetra Pak packaging components, i.e. separate paper from polyethylene/aluminium (PolyAl). The paper recovered from the UBCs is used as raw material for recycled paper production. As the separation of plastic from aluminium is a complex process, PolyAl is destined from paper recyclers to other companies named PolyAl recyclers. 
There are two types of companies that process PolyAl in Brazil: (a) producers that convert PolyAl into pellets, and then use plastic injection molding machines to make products for the promotional gift market (pens, key chains, rulers) and the domestic utility market (brooms, buckets); and (b) producers of roof tiles and plates, which absorb a much larger volume of PolyAl, being more advantageous for the recycling chain. There are 15 tiles and plates producers and 2 pellet producers in the recycling chain.

The biggest PolyAl recycler of Tetra Pak UBC in Brazil provides a successful example of a roof tiles and plates producer. They worked together with Tetra Pak and local universities to develop an award-winning roofing tile that received the EcoDesign award from the Federation of Industries of São Paulo State as recognition for the development of a sustainable innovative product. The company has 18 machines installed and has the capacity to use 400 tons of PolyAl per month. Tetra Pak is also involved in the production process, dedicating one person that provides support to the PolyAl recyclers in order to solve production problems and support with training. Equipment is also lent to PolyAl recyclers to improve process and productivity.

\subsubsection{Collaboration with waste collecting cooperatives}

In Brazil, waste collecting cooperatives are important players in the Tetra Park's circular supply chain. They are responsible for collecting recyclable waste, sorting and separating according to the type of material. They also compress the UBCs in press machines and sell the compressed packages to the paper recycling companies. Cooperatives are formal selforganised associations of waste pickers, which positively impacts in higher volumes of collected materials and give them better chance to make more money. This type of association is stimulated by Brazilian's waste regulations, which consider these companies as formal agents of the public cleaning service and important to recycling ecosystems.

Tetra Pak Brazil is supporting cooperatives in several ways: (1) lending equipment and press machines; (2) training and organising workshops with specific themes, involving other participants of the recycling chain; (3) investing in a program to increase their productivity, supporting the improvement of cooperative management; there are a group of Tetra Pak consultants that diagnosis a cooperative and identifies opportunities for improvement, such as change of lay out and deployment of a third shift; and (4) investing in programs to increase their professionalism, forming leaders. The President of one of the cooperatives mentioned that "...throughout this time of partnership with Tetra Pak (around 14 years) we have learned a lot... the management of the cooperative today is done in a much clearer, transparent way, we have learned to plan, organise and set goals, and try to achieve our goals".

Tetra Pak UBCs can reach the cooperatives in two different ways. One way is through selective door to door collection performed by some cities through waste collection companies that deliver the collected materials to the cooperatives. The other way is via individual end consumers who carry recyclable material to a cooperative or to voluntary collection points located in the retailers from where UBCs can be collected by a cooperative. A good example comes from one of the cooperatives that operate in one of the most populous regions of São Paulo city, the Southern region. The cooperative currently collects 450 tons of recyclable materials per month and has 47 members. In addition, the cooperative collects recyclable materials from 160 specific collecting points located in large residential buildings as well as several schools and supermarkets that are not served by public collection.

Recognizing the critical importance of these collection points for its circular supply chain, Tetra Pak Brazil developed a website (www.rotadareciclagem.com.br) that provides the population with information about the specific location of 4,400 points mapped by the company, including cooperatives, associations, voluntary delivery points and recyclable 
materials trades distributed throughout Brazil.

\subsubsection{Engaging with end consumers}

Tetra Pak recognises that end consumers play an important role in their circular supply chain ecosystem. As the company's Environmental Director puts it, "What makes the difference is the consumer. If the consumer wants to do selective collection, he does, if he thinks he does not want it...it's complicated to educate after he is an adult".

With this perspective in mind, since 1997 Tetra Pak has maintained an educational program called "Environmental Culture in Schools", which seeks to educate students and teachers about selective waste collection, recycling, urban solid waste management and material life cycle. The project also has an internet portal, which gathers content focused on topics such as environmental education, citizenship, and selective collection and recycling. It is based on the belief the students will spread this knowledge in their homes.

Recently Tetra Pak has learned that communication based on the social dimension is more effective. For example, communicating that recycling UBCs will support a significant number of families to get some income mobilizes end consumers to do selective disposal of UBCs. Most of the communication is done through internet and public events which usually have the participation of cooperatives as well.

\subsubsection{Engaging with business customers and retailers}

The main business customers of Tetra Pak Brazil are food processing companies operating in diverse segments such as milk, juices, soy drinks, coconut water, flavoured milks, culinary products and sauces. Most of them consider Tetra Pak as a main supporting source for environmentally friendly initiatives. Indeed, Tetra Pak customers usually get free consulting provided by the company's environmental department, which advises customers on how to improve their environmental performance. This is illustrated by the Tetra Pak's Supply Chain Director, who commented that they usually advise customers on how "...they can spend less water, throw less effluent, treat their effluent...for example, if you take a milk industry, it has to treat the effluents, the packaging that does not work it has to throw away, so we do a lot of work to assist them in this regard".

Some retailers are engaging in the recycling chain by offering space in their shops as 'delivery points' where consumers can leave their recyclable waste. These initiatives are widely communicated through the main media.

\subsubsection{Main challenges faced by Tetra Pak Brazil}

Tetra Pak Brazil considers end consumers the weakest link in its circular supply chain. The company recognises that end consumers play an important role in separating UBCs for selective collection by the waste collection companies or returning them directly to waste collecting cooperative or to a specific collection point location. However, part of the population still does not know that UBCs are recyclable. For the Environmental Director of Tetra Pak Brazil, a major challenge is to change the habits of the population, particularly adults, from a passive to a more active behaviour towards selective disposal. The company continues with an active communication program to disseminate the recyclability of Tetra Pak package and the idea of selective collection.

Tetra Pak Brazil points out that lack of public infrastructure facilitating selective disposal hinders end consumers engagement with selective disposal. Only $15 \%$ of the Brazilian population has access to selective collection facilities and amenities (e.g. selective bins). Furthermore, there is no selective collection in all Brazilian municipalities and the ones that 
provide it do not usually reach all areas of their municipalities.

Another challenge relates to the taxation system applied to recycled products in Brazil. Secondary products (i.e. finished products from recycled materials) are not exempt from tax. The consequence of such taxation system is that companies operating in the recycling sector have neither access to tax credits nor selling price advantage. For instance, when a company sells finished recycled products made out of secondary materials (waste and related byproducts), it has to pay the full tax that applies for all finished products (new or secondary) in Brazil without having tax compensations. This process hinders the competitiveness of the recycling sector in the country. In the words of a Managing Director of one of the recyclers, "...when I take material that was going to be thrown away in landfill, and I recycle, generate jobs, make the production chain, give warranty and product quality, and then I am taxed like a car maker or like any company, there is no differential for me... Since the long-life package was made it was already taxed... the packaging, the paper, all of the value chain. When I recycle what was going to be thrown away, I am taxed again, it returns all tax burden... You are taxed like any other company... I want differentiation".

Overall, the study provides a rich set of learning points that represent valuable insights to improve Tetra Pak packaging recycling rates in China and Brazil. Table 1 provides a cross case comparison of the research findings, presenting a summary of the main similarities and differences found between Tetra Pak China and Tetra Pak Brazil. The table offers a characterisation of key operational and contextual aspects concerning the development of Tetra Pak's circular supply chain across both countries.

Table 1. Cross case comparison

\begin{tabular}{|c|c|c|}
\hline Differences & Tetra Pak China & Tetra Pak Brazil \\
\hline \multirow[t]{2}{*}{ Selective collection } & Based on individual waste pickers. & $\begin{array}{l}\text { Based on cooperatives of waste pickers. } \\
\text { Participation of public door to door } \\
\text { selective collection is small (serving } 15 \% \\
\text { of the population) }\end{array}$ \\
\hline & $\begin{array}{l}\text { Informal. There are no formally } \\
\text { organised firms. }\end{array}$ & $\begin{array}{l}\text { Formal. Cooperatives are formally } \\
\text { organised firms, but they need support to } \\
\text { organise and manage their business. }\end{array}$ \\
\hline $\begin{array}{l}\text { Subsidies on recycling } \\
\text { chain }\end{array}$ & $\begin{array}{l}\text { Provides subsidies mainly on } \\
\text { recyclers by lending specialised } \\
\text { equipment. }\end{array}$ & $\begin{array}{l}\text { Provides subsidies on cooperatives and } \\
\text { PolyAl recyclers through lending } \\
\text { equipment. }\end{array}$ \\
\hline UBCs recycling process & $\begin{array}{l}\text { Process 1: separates each item (paper, } \\
\text { plastic, aluminium) to produce } \\
\text { secondary products. } \\
\text { Process } 2 \text { : process UBCs as a whole } \\
\text { to produce secondary products. }\end{array}$ & $\begin{array}{l}\text { Only separates paper from PolyAl (plastic } \\
\text { and aluminium), which continues bonded } \\
\text { together to produce secondary products. }\end{array}$ \\
\hline $\begin{array}{l}\text { Sourcing of raw } \\
\text { materials }\end{array}$ & $\begin{array}{l}\text { It imports supplementary materials } \\
\text { from external markets. }\end{array}$ & $\begin{array}{l}\text { It sources } 100 \% \text { of its raw materials from } \\
\text { local suppliers. }\end{array}$ \\
\hline Secondary products & $\begin{array}{l}\text { Process 1: recycled paper, plastic and } \\
\text { aluminium. } \\
\text { Process 2: secondary products as } \\
\text { fences and furniture made of } \\
\text { processed UBCs. }\end{array}$ & $\begin{array}{l}\text { Recycled paper. } \\
\text { Roof tiles, plates, brooms, buckets and } \\
\text { pens made of PolyAl. }\end{array}$ \\
\hline
\end{tabular}




\begin{tabular}{|l|l|l|}
\hline Regulation & $\begin{array}{l}\text { Recycling and solid waste } \\
\text { management regulation is still under } \\
\text { development. }\end{array}$ & $\begin{array}{l}\text { There is a national regulation for recycling } \\
\text { and solid waste management. Although } \\
\text { this regulatory basis stipulates } \\
\text { responsibilities, it fails to establish } \\
\text { penalties. There is a need of enforcement. }\end{array}$ \\
\hline Similarities & Tetra Pak China & Tetra Pak Brazil \\
\hline Leadership role & $\begin{array}{l}\text { Both have a leadership role to shape the circular supply chain, developing and } \\
\text { recycling ecosystems. }\end{array}$ \\
\hline $\begin{array}{l}\text { Multi-stakeholder } \\
\text { engagement }\end{array}$ & $\begin{array}{l}\text { Both engage and orchestrate relationships with various stakeholders to create the } \\
\text { circular supply chain. }\end{array}$ \\
\hline $\begin{array}{l}\text { Dissemination of } \\
\text { knowledge }\end{array}$ & \begin{tabular}{l} 
Both disseminate knowledge related with recycling to all stakeholders involved. \\
\hline Recycling processes
\end{tabular} & $\begin{array}{l}\text { UBCs in the circular supply chain of both countries are processed either as separate } \\
\text { commodities or as a whole material to the used as inputs for the production of } \\
\text { secondary products. }\end{array}$ \\
\hline $\begin{array}{l}\text { Rack of public } \\
\text { infrastructure }\end{array}$ & $\begin{array}{l}\text { While Tetra Pak China reached 28\% in 2015, tetra Pak Brazil reached 23.3\% in } \\
\text { rates. Both companies still have significant room for increasing their recycling }\end{array}$ \\
\hline
\end{tabular}

\section{Discussion}

The circular supply chain model presented in Figure 1 provides a useful framework for the development of a comparative analysis of Tetra Pak's circular supply chains in China and Brazil, helping to reveal valuable learning points in terms of similarities and differences between the two emerging economies. We elaborate on the main learning points of the study by deriving practical or managerial implications that can be valuable for companies developing similar circular supply chain initiatives.

For instance, looking at the diagrammatical representations of the circular flows Tetra Pak has implemented in China (Figure 3) and Brazil (Figure 4), it is possible to conclude that the company's circular supply chain in both countries are fairly similar in terms of design. This is evidence that Tetra Pak has replicated standardised sustainable supply chain initiatives across the two countries.

More specifically, the archetypal representations of the circular supply chains in China and Brazil reveal that Tetra Pak adopts standardised supply chain management practices across different international contexts in order to improve the sustainability of its supply chains. Furthermore, the circular supply chains enabling packaging recovery flows in both countries are predominantly characterised by open-loops involving third-party companies engaged with cascading processes. This is explained by the fact that Tetra Pak does not produce packaging products derived from recycled materials. Indeed, the relationship of Tetra Pak with its main distributors in both countries did not change after the introduction of the circular supply chains. The capture and recycling of UBCs is therefore implemented by a network of third-party actors.

A further aspect is that the standardised processes replicated in both countries are implemented by different actors in certain parts of the supply chain. Specifically, the 
archetypal circular supply chain representations (Figures 3 and 4) reveal some differences between China and Brazil in terms of the composition of the network of actors. A specific distinction in this respect is the presence of waste pickers in China and waste collection and cooperatives in Brazil. Despite these differentiations, the recovery processes implemented in the supply chains are similar, which shows that Tetra Pak has capitalised on the strengths of local players to implement the standardised supply chain sustainability practices the company developed in both countries. Finally, the archetypal representation of the circular supply chain in Brazil reveals a closed-loop representing packaging returns from end consumers to retailers. Such loop is not present in the circular supply chain of Tetra Pak in China. This loop can however be replicated in China if the Chinese Tetra Pak encourages end consumers and local retailers to implement similar sustainability initiatives developed in Brazil. Table 2 provides a comparison of the main roles stakeholders play in the circular supply chain of Tetra Pak in both countries.

Table 2. Key roles of stakeholders in the circular supply chains of China and Brazil

\begin{tabular}{|c|c|c|}
\hline Key stakeholders & Stakeholders' roles in China & Stakeholders' roles in Brazil \\
\hline Recyclers & $\begin{array}{l}\text { SME companies act as the main } \\
\text { providers of secondary input materials } \\
\text { derived from UBCs to manufacturers in } \\
\text { the market. They get UBC inputs from } \\
\text { cascading processes (open-loops) } \\
\text { originated from Tetra Pak (production } \\
\text { waste), food processing companies } \\
\text { (production waste) and waste collecting } \\
\text { companies (UBC collection). Some } \\
\text { SMEs have their operations exclusively } \\
\text { dedicated to processing UBCs. } \\
\text { Some paper mills companies are now } \\
\text { producing recycled paper derived from } \\
\text { UBCs. }\end{array}$ & $\begin{array}{l}\text { Compared to China, Brazil has a larger } \\
\text { number of paper mills actively producing } \\
\text { recycled paper derived from UBCs. } \\
\text { SME companies provide secondary raw } \\
\text { materials derived from UBCs to } \\
\text { manufacturers in the market. None of the } \\
\text { SMEs are exclusively dedicated to } \\
\text { processing UBCs. } \\
\text { Two recyclers develop large scale } \\
\text { production capability to process PolyAl } \\
\text { materials extracted from UBCs for the } \\
\text { manufacturing of recycled products based } \\
\text { on polyethylene and aluminium. } \\
\text { Similarly to China, recyclers in Brazil get } \\
\text { UBC inputs from cascading processes } \\
\text { (open-loops) originated from Tetra Pak } \\
\text { (production waste), food processing } \\
\text { companies (production waste) and waste } \\
\text { collecting companies (UBC collection). }\end{array}$ \\
\hline Waste collectors & $\begin{array}{l}\text { Individual waste pickers are a major work } \\
\text { force to collect UBCs. They trigger open- } \\
\text { loop flows of UBCs from end consumers } \\
\text { to waste collecting companies (middle } \\
\text { collectors). By their turn, waste collecting } \\
\text { companies, which are mainly SMEs, } \\
\text { enable open-loops of UBCs from end } \\
\text { consumers, waste pickers, retailers and } \\
\text { food processing companies to recyclers. }\end{array}$ & $\begin{array}{l}\text { Waste collection companies play an } \\
\text { important role in making selective } \\
\text { collection that enables open-loops of } \\
\text { UBCs from end consumers (households } \\
\text { and businesses) to waste collecting } \\
\text { cooperatives, which are key players in the } \\
\text { circular supply chain. These cooperatives } \\
\text { have pre-processing (sorting and pressing) } \\
\text { capabilities to enable open-loop of UBCs } \\
\text { from end consumers, waste collection } \\
\text { companies, retailers and food processing } \\
\text { companies to recyclers. }\end{array}$ \\
\hline
\end{tabular}




\begin{tabular}{|l|l|l|}
\hline End consumers & $\begin{array}{l}\text { They are the main source of UBC open- } \\
\text { loop flows to waste pickers and collecting } \\
\text { companies. }\end{array}$ & $\begin{array}{l}\text { They are the main source of UBC open- } \\
\text { loop flows to waste collection service } \\
\text { companies and waste collecting } \\
\text { cooperatives. They also trigger a close- } \\
\text { loop of UBCs back to retailers. }\end{array}$ \\
\hline Retailers & $\begin{array}{l}\text { They trigger open-loop flows of UBCs } \\
\text { into waste collecting companies. }\end{array}$ & $\begin{array}{l}\text { They trigger open-loop flows of UBCs } \\
\text { into waste collecting cooperatives. They } \\
\text { also mediate the cascading of UBCs from } \\
\text { closed-loops triggered by end consumers } \\
\text { (households). That is, retailers convert } \\
\text { closed-loops of UBCs from household } \\
\text { consumers into open-loops of UBCs to the } \\
\text { cooperatives. }\end{array}$ \\
\hline
\end{tabular}

Because Tetra Pak's circular supply chains in China and Brazil are highly dependent on third-party players, the company's leadership role to develop external capabilities and facilitate collaborations among players is of critical importance. In fact, the study revealed the decisive leadership role played by Tetra Pak in both countries. The leadership of organisations developing strategic business ecosystems is fundamental, as they have strong influence on the development of key processes enabling the ecosystem operations (Zahra and Nambisan 2012). This was indeed crucial to the implementation of the circular supply chain supporting UBC recovery ecosystems in China and Brazil. Tetra Pak in both countries actively provides key stakeholders in the supply chain with technical advice, training and equipment to support key UBC recovery flow processes such as collection, sorting, pressing and processing of UBCs. The company also formally acknowledges outstanding performance of collectors through award systems. These aspects illustrate the Tetra Pak's leadership role in shaping the circular supply chain supporting the company's packaging recovery ecosystem in both countries. Such evidence corroborates previous findings by Gosling et al. (2016), who suggest that supply chain leadership is critical in creating sustainable supply chains. To reinforce theory acknowledging the fundamental importance of leadership in the organisation of third party actors to support material recovery ecosystems, as well as to position theory in the context of circular supply chain design, we formally elaborate the following theoretical proposition:

\section{P1: Circular supply chain design requires a leading organisation to orchestrate the engagement of third party actors with processes that systematically implement material recovery flows.}

The leadership role above mentioned includes the development and facilitation of collaborations between key stakeholders in order to enable recovery flows of materials in a purposeful manner. The systematic way in which these collaborations are developed can be related to purposive supply chain design initiatives involving the development of strategic relationships with the right players to perform specific roles in the supply chain (Fawcett and Waller 2014).

This is evidenced by Tetra Pak's initiatives to engage with recyclers, collectors, customers, retailers, end consumers and other stakeholders as described in the previous sections. For example, Tetra Pak in China developed active partnerships with shopping centres, newspapers and schools in order to promote the recycling capabilities inherent in its UBCs, while in Brazil the company supported the creation of packaging collection points to 
enable more active participation of retailers in packaging recovery ecosystems, including the development of a website and apps to support utilization of the system.

Recent studies have acknowledged the importance of such collaborations in the implementation of circular supply chains. For instance, De Angelis, Howard, and Miemczyk (2018, p.17) conceptually suggest that "circular supply chains are enabled by close supply chain collaboration with partners within and beyond their immediate industrial boundaries, including suppliers, product designers and regulators." Our two cases provide empirical evidence to support this statement and we formally elaborate on it through the following related propositions:

\section{P2a: A circular supply chain requires the establishment of collaborations with third party actors within and beyond the immediate industrial boundaries of the supply chain.}

Evidence for this proposition is manifested on the collaborations that Tetra Pak developed not only with key stakeholders that are directly involved in the circular supply chain operations (Table 2), but also with external institutions such as universities, schools, shopping centres, and other external actors as mentioned previously. A corollary and theoretical expansion of proposition $\mathrm{P} 2 \mathrm{a}$ is:

\section{P2b: A circular supply chain requires the development of collaborations not only between the focal firm and its stakeholders, but also collaborations between stakeholders.}

The research findings in Section 4 illustrate how Tetra Pak has been developing collaborations with key stakeholders in the circular supply chain. In terms of collaborations between stakeholders, a specific example is the initiative of a dairy processor in China to collaborate with supermarkets to implement the 'paid packaging recycling' campaign, as mentioned in Section 4.1.4.

Based on the study findings, from a wide supply chain perspective it is evident that Tetra Pak's supply chain presents the same 'linear' central or backbone configuration in both countries. However, the 'circular' configuration of the supply chain, which involves further local stakeholders enabling the recovery ecosystem structure for Tetra Pak UBCs, presents some variations.

Brazil for example has a more formal network structure to recover UBCs via waste collection service companies and cooperatives, whilst China relies on a more informal network of waste pickers and waste collecting SMEs. Another aspect is that the retailers in Brazil play a more active role in the recovery ecosystem by providing packaging collection points for household end consumers on an ongoing basis, whilst in China there are no similar initiatives by local supermarkets. From a circular supply chain perspective this represents a closed-loop flow linking end consumers and retailers in Brazil, while in China there are no such closed-loops.

Further findings show that the selective waste classification system established in Brazil facilitates door to door collection of recyclable materials, including UBCs. This speeds up waste sorting and separation processes executed by the waste collecting cooperatives. As China still does not have a clearly established waste classification system, sorting and separation of packaging from waste collected requires more operational efforts from waste pickers and collectors.

Indeed, Brazil has a specific national legislation for solid waste management that 
establishes the shared responsibility of manufacturers, importers, distributors, traders, retailers, consumers, and public agents in the integrated management of urban solid waste. The law promotes the practice of sustainable consumption habits and introduces instruments to increase recycling and reuse of solid waste. This might explain why we have found closedloops linking stakeholders downstream Tetra Pak's circular supply chain in Brazil and not in China. From this we infer that the differences between the two countries' legal environment influence the structure of the circular supply chains analysed. Thus we propose that:

\section{P3: The external legal framework environment has a determinant influence on the network structure of circular supply chains.}

The legal framework represents the cognitive, normative, and regulative pillars of the institutional environment of the host country (Wu and Jia 2018), this way facilitating or hindering the implementation of loops connecting circular supply chain actors. The establishment of the legal framework is beyond Tetra Pak's control, which posits further challenges to the design of the circular supply chain. In China for example the government needs to establish clear garbage classification rules and frameworks that regulate and provide standard references that can 'formalise' the informal waste collection sector. There is also need to implement extended producer responsibility rules to include the food packaging sector, food processing companies, distributors and the retail channel. In Brazil for example, Tetra Pak had the opportunity to influence the government during the formulation of the solid waste law and proposals to extended responsibility and intense use of cooperatives. Nonetheless, the government still needs to monitor and reinforce the implementation of existing recycling rules by implementing more favorable taxation policies and incentives to recyclers and related cooperatives. We acknowledge the fundamental importance of policies and incentives to facilitate transitions from the linear to the circular economy by elaborating the following proposition:

\section{P4: The shift from the linear to the circular economy requires government policies to evolve along and support circular supply chain practices.}

Another important research finding reveals that Tetra Pak in China seems to be more active than its counterpart in Brazil in terms of developing public awareness on the recyclability of UBCs. In China, the company has been developing a series of partnerships with retailers, schools and food processing companies to develop public campaigns as well as specific events targeted to end consumers and other key stakeholders in the circular supply chain. Tetra Pak Brazil tends to rely more on specific actions such as education in schools and website campaigns promoting recycling. As mentioned, one example on this direction is the website they developed to provide the population with online resources to locate packaging collection points around the country and promote the awareness campaigns they started to lead. Overall, the campaigns Tetra Pak has been developing in both countries to improve public awareness on the importance and benefits of waste recycling seem to be producing positive results in terms of improving recycling rates. We therefore propose that:

\section{P5: The development of awareness campaigns is a key initiative to reinforce and promote the creation of materials recovery flows necessary to the implementation of circular supply chains.}

Finally, Tetra Pak in China and Brazil invest in R\&D for technological recycling 
innovations. Overall, their initiatives in both countries have led to fairly similar recycling rates (28\% in China and 23.3\% in Brazil). Much has been achieved in both countries. Yet, the recycling rates under $30 \%$ indicate that much work still remains to be done considering the large volume of UBCs generated by the populations in both countries.

The overall research findings discussed above provide a series of key managerial insights that can be taken into account by businesses concerned with the implementation of circular supply chains aimed at supporting material recovery ecosystems. In general they offer a helpful basis of important points for decision makers to consider when planning strategic and operational initiatives that are relevant in the design of circular supply chains. A summarised list of the key managerial insights derived from the study is presented below in a more elaborated way:

- Purposive design of the supply chain considering the strategic roles that key players in the supply chain can play to systematically execute specific material recovery processes in the long term.

- Adoption of initiatives to develop skills and capabilities of key supply chain players, e.g. knowledge transference (training), technological support/advice.

- Facilitation of collaborations among supply chain players in a purposeful way, enhancing their collective ability to provide continuous flow of materials in the supply chain.

- Development of wider partnerships with players external to the supply chain (e.g. shopping centres, supermarkets, schools, universities, local authorities, civil associations, etc.), for the creation of public campaigns, specific events and collection points to enhance public awareness and support waste collection processes.

- Establishment of formal award mechanisms to acknowledge outstanding performance of waste collectors.

- Replication of standardised sustainable supply chain initiatives across different regions/countries.

- Build upon the strengths of local players to implement the standardised sustainable supply chain initiatives across different regions/countries.

- Consider R\&D investments on technologies and innovations that can improve the overall materials recovery capacity of the supply chain in the long term.

\section{Conclusion}

The present study makes relevant contributions to the understanding of the supply chain capabilities supporting materials recovery ecosystems implemented in the packaging industry. Such ecosystems are by nature more complex than traditional linear value chain systems, due to the necessary inclusion of additional players and processes implementing circular flows of materials. In the circular economy context such circularity is fundamental.

Accordingly, we developed the study with basis on a circular supply chain archetype that provides a helpful conceptual framework that allows the representation of complex structure of supply chain actors and their related interconnections in terms of closed- and open-loop flows of materials. The framework also provides a valuable referential basis for the development of comparative analysis. 
In this respect, we applied the circular supply chain framework as a basis to develop a comparative analysis of packaging recovery ecosystems implemented by Tetra Pak, a prime global player in the packaging industry, in its operations in China and Brazil. Bringing industrial practice perspectives from these two strong emerging economies adds to the practical contributions offered in this paper. The research outcomes here reported provide references, learning points, practical insights, specific recommendations and propositions that are valuable for academics and practitioners interested in the Chinese and Brazilian markets as well as in sustainability perspectives from the packaging industry.

For instance, from a theoretical perspective the paper offers a conceptual characterisation of circular supply chains that can be applied to support further comparative studies of materials recovery flows in different regions, sectors and supply chains. From a practical perspective, the propositions stated in the paper offer a set of managerial recommendations concerning supply chain design, leadership and collaborations that can facilitate the implementation of circular supply chains by other businesses. For example, to improve the circular flows of materials recovered after use, the paper points out the importance of developing and promoting collaborations with third-party organisations beyond the boundaries of the focal company's operations, including cascading of materials into further supply chains.

As in all qualitative studies, we acknowledge the conclusions derived in the research are limited to the regional contexts where the study was developed and we cannot generalise the research findings to contexts other than the ones considered. For this reason, we do welcome and encourage the development further research that applies the circular supply chain framework in other regional or industrial contexts, adding to the outcomes of the present study. Another limitation of the study is the lack of quantitative data related to specific volumes of each recycling loop. Such data could provide interesting insights on volume variations across different loops in the circular supply chain.

It would also be interesting the development of further research that investigates the restorative capability of the products derived from the recycling processes identified in this research. For example, in Brazil the roofing tiles produced from Tetra Pak packaging are a successful example of the recycling alternatives for the company's UBCs. It would be relevant to carry out research on whether Tetra Pak recycled products can be further recycled or whether they can potentially impact the environment. This would add interesting insights on the circularity potential of Tetra Pak packaging and related derivatives.

\section{References}

Akturk, M. Serkan, James D. Abbey, and H. Neil Geismar. 2017. "Strategic Design of Multiple Lifecycle Products for Remanufacturing Operations.” IISE Transactions 49 (10). Taylor \& Francis: 967-79. doi:10.1080/24725854.2017.1336684.

Badurdeen, Fazleena, Deepak Iyengar, Thomas J. Goldsby, Haritha Metta, Sonal Gupta, and I.S. Jawahir. 2009. "Extending Total Life-Cycle Thinking to Sustainable Supply Chain Design." International Journal of Product Lifecycle Management 4 (1/2/3): 49. doi:10.1504/IJPLM.2009.031666.

Bals, Lydia, and Wendy L. Tate. 2018. "Sustainable Supply Chain Design in Social Businesses: Advancing the Theory of Supply Chain." Journal of Business Logistics 39 (1). Wiley-Blackwell: 57-79. doi:10.1111/jbl.12172.

Batista, Luciano, Michael Bourlakis, and Roger Maull. 2016. "Business Models in the Circular Economy and the Enabling Role of Supply Chains." In 23rd European Operations Management Association (EurOMA). Trondheim, Norway, 17- 22 June.

Batista, Luciano, Michael Bourlakis, Palie Smart, and Roger Maull. 2018. "In Search of a Circular Supply Chain Archetype - a Content-Analysis-Based Literature Review." Production Planning \& Control 29 (6). Taylor \& Francis: 438-51. doi:10.1080/09537287.2017.1343502. 
Beske, Philip, and Stefan Seuring. 2014. "Putting Sustainability into Supply Chain Management." Edited by Dr Stefan Schaltegger, Prof Roger Burr. Supply Chain Management: An International Journal 19 (3). Emerald Group Publishing Limited: 322-31. doi:10.1108/SCM-12-2013-0432.

Brandenburg, Marcus, and Tobias Rebs. 2015. "Sustainable Supply Chain Management: A Modeling Perspective.” Annals of Operations Research 229 (1). Springer US: 213-52. doi:10.1007/s10479-015-18531.

Bryman, Alan, and Emma Bell. 2015. Business Research Methods. 4th Ed. Oxford: Oxford University Press.

Calleja, Gema, Albert Corominas, Carme Martínez-Costa, and Rocío de la Torre. 2018. "Methodological Approaches to Supply Chain Design.” International Journal of Production Research 56 (13). Taylor \& Francis: 4467-89. doi:10.1080/00207543.2017.1412526.

Cannella, Salvatore, Manfredi Bruccoleri, and Jose M. Framinan. 2016. "Closed-Loop Supply Chains: What Reverse Logistics Factors Influence Performance?” International Journal of Production Economics 175: 3549. doi:10.1016/j.ijpe.2016.01.012.

Cimren, Emrah, Joseph Fiksel, Marc E. Posner, and Kieran Sikdar. 2011. "Material Flow Optimization in ByProduct Synergy Networks.” Journal of Industrial Ecology 15 (2): 315-32. doi:10.1111/j.15309290.2010.00310.x.

Coelho, T. M., R. Castro, and J. A. Gobbo. 2011. "PET Containers in Brazil: Opportunities and Challenges of a Logistics Model for Post-Consumer Waste Recycling." Resources, Conservation and Recycling 55 (3). Elsevier: 291-99. doi:10.1016/j.resconrec.2010.10.010.

Cooper, Martha C., Douglas M. Lambert, and Janus D. Pagh. 1997. "Supply Chain Management: More Than a New Name for Logistics.” The International Journal of Logistics Management 8 (1). MCB UP Ltd: 1-14. doi:10.1108/09574099710805556.

Das, Kanchan, and Nageswara R. Posinasetti. 2015. "Addressing Environmental Concerns in Closed Loop Supply Chain Design and Planning." International Journal of Production Economics 163: 34-47. doi:10.1016/j.ijpe.2015.02.012.

De Angelis, R, MB Howard, and J Miemczyk. 2018. "Supply Chain Management and the Circular Economy: Towards the Circular Supply Chain.” Production Planning and Control 29 (6): 425-37.

Dervojeda, K, D Verzijl, E Rouwmaat, L Probst, and L Frideres. 2014. "Clean Technologies - Circular Supply Chains.” EU Directorate-General for Enterprise and Industry, Brussels: European Union.

Dües, Christina Maria, Kim Hua Tan, and Ming Lim. 2013. "Green as the New Lean: How to Use Lean Practices as a Catalyst to Greening Your Supply Chain.” Journal of Cleaner Production 40: 93-100. doi:10.1016/j.jclepro.2011.12.023.

Elkington, John. 1998. Cannibals with Forks: The Triple Bottom Line of 21st Century Business. Conscientious Commerce. New Society Publishers. https://books.google.co.uk/books?id=dIJAbIM7XNcC.

EM Foundation. 2012. "Towards the Circular Economy Vol.1: Economic and Business Rationale for an Accelerated Transition.” Ellen MacArthur Foundation Report, Cowes, Isle of Wight. http://www.ellenmacarthurfoundation.org/assets/downloads/publications/Ellen-MacArthur-FoundationTowards-the-Circular-Economy-vol.1.pdf.

2014. "Towards the Circular Economy - Volume 3: Accelerating the Scale-up across Global Supply Chains.” Ellen MacArthur Foundation Report, Cowes, Isle of Wight.

Eskandarpour, Majid, Pierre Dejax, Joe Miemczyk, and Olivier Péton. 2015. "Sustainable Supply Chain Network Design: An Optimization-Oriented Review.” Omega 54 (July). Pergamon: 11-32. doi:10.1016/J.OMEGA.2015.01.006.

EU Commission. 2015. "Closing the Loop - An EU Action Plan for the Circular Economy." Communication 0614, Brussels.

Fabbe-Costes, Nathalie, Christine Roussat, Margaret Taylor, and Andrew Taylor. 2014. "Sustainable Supply Chains: A Framework for Environmental Scanning Practices." International Journal of Operations \& Production Management 34 (5). Emerald Group Publishing Limited: 664-94. doi:10.1108/IJOPM-10-20120446. 
Fahimnia, Behnam, Joseph Sarkis, Angappa Gunasekaran, and Reza Farahani. 2017. "Decision Models for Sustainable Supply Chain Design and Management." Annals of Operations Research 250 (2). Springer US: 277-78. doi:10.1007/s10479-017-2428-0.

Fawcett, Stanley E., and Matthew A. Waller. 2014. "Supply Chain Game Changers-Mega, Nano, and Virtual Trends-And Forces That Impede Supply Chain Design (i.e., Building a Winning Team).” Journal of Business Logistics 35 (3). Wiley-Blackwell: 157-64. doi:10.1111/jbl.12058.

Geissdoerfer, Martin, Paulo Savaget, Nancy M.P. Bocken, and Erik Jan Hultink. 2017. "The Circular Economy - A New Sustainability Paradigm?” Journal of Cleaner Production 143: 757-68. doi:10.1016/j.jclepro.2016.12.048.

Genovese, Andrea, Adolf A. Acquaye, Alejandro Figueroa, and S.C. Lenny Koh. 2017. "Sustainable Supply Chain Management and the Transition towards a Circular Economy: Evidence and Some Applications." Omega 66 (January): 344-57. doi:10.1016/j.omega.2015.05.015.

Giarini, Orio, and Walter R. Stahel. 1989. The Limits to Certainty: Facing Risks in the New Service Economy. Kluwer Academic Publishers.

Golini, Ruggero, Antonella Moretto, Federico Caniato, Maria Caridi, and Matteo Kalchschmidt. 2017. "Developing Sustainability in the Italian Meat Supply Chain: An Empirical Investigation." International Journal of Production Research 55 (4). Taylor \& Francis: 1183-1209. doi:10.1080/00207543.2016.1234724.

Gong, Yu, Fu Jia, Steve Brown, and Lenny Koh. 2018. "Supply Chain Learning of Sustainability in Multi-Tier Supply Chains." International Journal of Operations \& Production Management 38 (4). Emerald Publishing Limited : 1061-90. doi:10.1108/IJOPM-05-2017-0306.

Gosling, Jonathan, Fu Jia, Yu Gong, and Steve Brown. 2016. "The Role of Supply Chain Leadership in the Learning of Sustainable Practice: Toward an Integrated Framework.” Journal of Cleaner Production 137 (November). Elsevier: 1458-69. doi:10.1016/J.JCLEPRO.2014.10.029.

Govindan, Kannan, Jyoti Dhingra Darbari, Vernika Agarwal, and P C Jha. 2017. "Fuzzy Multi-Objective Approach for Optimal Selection of Suppliers and Transportation Decisions in an Eco-Efficient Closed Loop Supply Chain Network.” Journal of Cleaner Production 165 (November). Elsevier Ltd: 1598-1619.

Govindan, Kannan, and Mia Hasanagic. 2018. “A Systematic Review on Drivers, Barriers, and Practices towards Circular Economy: A Supply Chain Perspective.” International Journal of Production Research 56 (1-2): 278-311. doi:10.1080/00207543.2017.1402141.

Govindan, Kannan, and Hamed Soleimani. 2017. "A Review of Reverse Logistics and Closed-Loop Supply Chains: A Journal of Cleaner Production Focus.” Journal of Cleaner Production 142 (January): 371-84. doi:10.1016/j.jclepro.2016.03.126.

Govindan, Kannan, Hamed Soleimani, and Devika Kannan. 2015. "Reverse Logistics and Closed-Loop Supply Chain: A Comprehensive Review to Explore the Future." European Journal of Operational Research 240 (3): 603-26. doi:10.1016/j.ejor.2014.07.012.

Guba, Egon G. 1981. "Criteria for Assessing the Trustworthiness of Naturalistic Inquiries.” Educational Communication \& Technology 29 (2). Springer US: 75-91. doi:10.1007/BF02766777.

Guide, V. Daniel R., and Luk N. Van Wassenhove. 2009. “OR FORUM-The Evolution of Closed-Loop Supply Chain Research.” Operations Research 57 (1). INFORMS : 10-18. doi:10.1287/opre.1080.0628.

Hage, Olle, and Patrik Söderholm. 2008. “An Econometric Analysis of Regional Differences in Household Waste Collection: The Case of Plastic Packaging Waste in Sweden." Waste Management 28 (10). Elsevier: 1720-31. doi:10.1016/J.WASMAN.2007.08.022.

Harland, C.M., N.D. Caldwell, P. Powell, and J. Zheng. 2007. "Barriers to Supply Chain Information Integration: SMEs Adrift of ELands.” Journal of Operations Management 25 (6). Elsevier: 1234-54. doi:10.1016/J.JOM.2007.01.004.

Hopewell, Jefferson, Robert Dvorak, and Edward Kosior. 2009. "Plastics Recycling: Challenges and Opportunities." Philosophical Transactions of the Royal Society of London. Series B, Biological Sciences 364 (1526). The Royal Society: 2115-26. doi:10.1098/rstb.2008.0311. 
Howard, Mickey, Peter Hopkinson, and Joe Miemczyk. 2018. "The Regenerative Supply Chain: A Framework for Developing Circular Economy Indicators.” International Journal of Production Research, September. Taylor \& Francis, 1-19. doi:10.1080/00207543.2018.1524166.

Jabbarzadeh, Armin, Behnam Fahimnia, and Fatemeh Sabouhi. 2018. "Resilient and Sustainable Supply Chain Design: Sustainability Analysis under Disruption Risks." International Journal of Production Research 56 (17): 5945-68. doi:10.1080/00207543.2018.1461950.

Jalil, Emy Ezura A., David B. Grant, John D Nicholson, and Pauline Deutz. 2016. "Reverse Logistics in Household Recycling and Waste Systems: A Symbiosis Perspective." Edited by Vikas Kumar, Marlene Amorim, Arijit Bhattacharya, and Jose Arturo Garza-Reyes. Supply Chain Management: An International Journal 21 (2). Emerald Group Publishing Limited: 245-58. doi:10.1108/SCM-02-2015-0056.

Jia, Fu, Laura Zuluaga-Cardona, Adrian Bailey, and Ximena Rueda. 2018. "Sustainable Supply Chain Management in Developing Countries: An Analysis of the Literature." Journal of Cleaner Production 189 (July). Elsevier: 263-78. doi:10.1016/J.JCLEPRO.2018.03.248.

Krikke, Harold, Ieke le Blanc, and Steef van de Velde. 2004. "Product Modularity and the Design of ClosedLoop Supply Chains.” California Management Review 46 (2).

Kuik, Swee S., Sev V. Nagalingam, and Yousef Amer. 2011. "Sustainable Supply Chain for Collaborative Manufacturing." Edited by K.L. Choy. Journal of Manufacturing Technology Management 22 (8). Emerald Group Publishing Limited: 984-1001. doi:10.1108/17410381111177449.

Lacy, Peter, and Jakob Rutqvist. 2015. Waste to Wealth: The Circular Economy Advantage. Basingstoke: Palgrave Macmillan.

Lambert, Douglas M., Martha C. Cooper, and Janus D. Pagh. 1998. "Supply Chain Management: Implementation Issues and Research Opportunities." The International Journal of Logistics Management 9 (2). MCB UP Ltd: 1-20. doi:10.1108/09574099810805807.

Leigh, Michael, and Xiaohong Li. 2015. "Industrial Ecology, Industrial Symbiosis and Supply Chain Environmental Sustainability: A Case Study of a Large UK Distributor." Journal of Cleaner Production 106 (November). Elsevier: 632-43. doi:10.1016/J.JCLEPRO.2014.09.022.

Lincoln, Yvonna S., and E G Guba. 1985. Naturalistic Inquiry. Vol. null. London: Sage Publications. https://books.google.co.uk/books/about/Naturalistic_Inquiry.html?id=2oA9aWlNeooC.

Linzner, Roland, and Stefan Salhofer. 2014. "Municipal Solid Waste Recycling and the Significance of Informal Sector in Urban China." Waste Management \& Research 32 (9): 896-907. doi:10.1177/0734242X14543555.

Lovins, Amory, and Michael Braungart. 2014. A New Dynamic - Effective Business in a Circular Economy. 2nd ed. Cowes, Isle of Wight: Ellen MacArthur Foundation Publishing.

Mishra, N., V. Kumar, and F.T.S. Chan. 2012. "A Multi-Agent Architecture for Reverse Logistics in a Green Supply Chain.” International Journal of Production Research 50 (9). Taylor \& Francis Group : 2396-2406. doi:10.1080/00207543.2011.581003.

Moore, James F. 2006. "Business Ecosystems and the View from the Firm." The Antitrust Bulletin 51 (1). SAGE PublicationsSage CA: Los Angeles, CA: 31-75. doi:10.1177/0003603X0605100103.

Murray, Alan, Keith Skene, and Kathryn Haynes. 2017. "The Circular Economy: An Interdisciplinary Exploration of the Concept and Application in a Global Context." Journal of Business Ethics 140 (3). Springer Netherlands: 369-80. doi:10.1007/s10551-015-2693-2.

Nasir, Mohammed Haneef Abdul, Andrea Genovese, Adolf A. Acquaye, S.C.L. Koh, and Fred Yamoah. 2017. "Comparing Linear and Circular Supply Chains: A Case Study from the Construction Industry." International Journal of Production Economics 183 (January): 443-57. doi:10.1016/j.ijpe.2016.06.008.

Niero, Monia, Michael Z. Hauschild, Simon B. Hoffmeyer, and Stig I. Olsen. 2017. "Combining Eco-Efficiency and Eco-Effectiveness for Continuous Loop Beverage Packaging Systems: Lessons from the Carlsberg Circular Community." Journal of Industrial Ecology 21 (3): 742-53. doi:10.1111/jiec.12554.

O’Connor, Megan P., Julie B. Zimmerman, Paul T. Anastas, and Desiree L. Plata. 2016. "A Strategy for Material Supply Chain Sustainability: Enabling a Circular Economy in the Electronics Industry through Green Engineering." ACS Sustainable Chemistry \& Engineering 4 (11). American Chemical Society: 5879- 
88. doi:10.1021/acssuschemeng.6b01954.

Overstreet, Robert E., Joe B. Hanna, Terry A. Byrd, Casey G. Cegielski, and Benjamin T. Hazen. 2013. "Leadership Style and Organizational Innovativeness Drive Motor Carriers toward Sustained Performance." The International Journal of Logistics Management 24 (2). Emerald Group Publishing Limited: 247-70. doi:10.1108/IJLM-12-2012-0141.

Pan, Shu-Yuan, Michael Alex Du, I-Te Huang, I-Hung Liu, E-E Chang, and Pen-Chi Chiang. 2015. "Strategies on Implementation of Waste-to-Energy (WTE) Supply Chain for Circular Economy System: A Review." Journal of Cleaner Production 108: 409-21. doi:10.1016/j.jclepro.2015.06.124.

Patton, Michael Quinn. 2015. Qualitative Research \& Evaluation Methods: Integrating Theory and Practice. 4th ed. London: Sage Publications Ltd.

Preston, Felix. 2012. "A Global Redesign? Shaping the Circular Economy.” Energy, Environment and Resource Governance, no. March: 20.

http://www.chathamhouse.org/sites/files/chathamhouse/public/Research/Energy, Environment and Development/bp0312_preston.pdf.

Sheriff, K. M.Mahaboob, Nachiappan Subramanian, Shams Rahman, and Jayanth Jayaram. 2017. "Integrated Optimization Model and Methodology for Plastics Recycling: Indian Empirical Evidence." Journal of Cleaner Production 153 (June). Elsevier: 707-17. doi:10.1016/j.jclepro.2016.07.137.

Stevens, Graham C. 1989. “Integrating the Supply Chain.” International Journal of Physical Distribution \& Materials Management 19 (8). MCB UP Ltd: 3-8. doi:10.1108/EUM0000000000329.

Su, Biwei, Almas Heshmati, Yong Geng, and Xiaoman Yu. 2013. "A Review of the Circular Economy in China: Moving from Rhetoric to Implementation." Journal of Cleaner Production 42 (March). Elsevier: 215-27. doi:10.1016/j.jclepro.2012.11.020.

Webster, Ken. 2015. The Circular Economy - a Wealth of Flows. Cowes, Isle of Wight: Ellen MacArthur Foundation Publishing.

Wu, Zhaohui, and Fu Jia. 2018. "Toward a Theory of Supply Chain Fields - Understanding the Institutional Process of Supply Chain Localization.” Journal of Operations Management In press (April). Elsevier. doi:10.1016/J.JOM.2018.03.002.

Yin, Robert. 2013. Case Study Research: Design and Methods. 5th Edition. London: Sage Publications Ltd.

Zahra, Shaker A., and Satish Nambisan. 2012. "Entrepreneurship and Strategic Thinking in Business Ecosystems.” Business Horizons 55 (3). Elsevier: 219-29. doi:10.1016/j.bushor.2011.12.004.

Zeng, Huixiang, Xiaohong Chen, Xu Xiao, and Zhifang Zhou. 2017. "Institutional Pressures, Sustainable Supply Chain Management, and Circular Economy Capability: Empirical Evidence from Chinese EcoIndustrial Park Firms.” Journal of Cleaner Production 155 (July). Elsevier Ltd: 54-65.

Zhang, Hua, and Zong Guo Wen. 2014. "The Consumption and Recycling Collection System of PET Bottles: A Case Study of Beijing, China.” Waste Management 34 (6). Pergamon: 987-98. doi:10.1016/j.wasman.2013.07.015.

Zhu, Qinghua, Yong Geng, and Kee-hung Lai. 2010. “Circular Economy Practices among Chinese Manufacturers Varying in Environmental-Oriented Supply Chain Cooperation and the Performance Implications.” Journal of Environmental Management 91 (6): 1324-31. doi:10.1016/j.jenvman.2010.02.013.

Zorzini, Marta, Linda C. Hendry, Fahian Anisul Huq, and Mark Stevenson. 2015. "Socially Responsible Sourcing: Reviewing the Literature and Its Use of Theory." International Journal of Operations \& Production Management 35 (1): 60-109. doi:10.1108/IJOPM-07-2013-0355. 


\section{Appendix}

Table 3. Composition of the managers group interviewed in China

\begin{tabular}{|c|c|c|}
\hline Company & Location & Managers interviewed \\
\hline $\begin{array}{l}\text { Tetra Pak } \\
\text { China }\end{array}$ & Shanghai & $\begin{array}{ll}\text { 1. } & \text { Vice-president (*2 times) } \\
\text { 2. } & \text { Cluster Environmental Director } \\
\text { 3. } & \text { Senior Environmental Engineer } \\
\text { 4. } & \text { Environmental Engineer }\end{array}$ \\
\hline Recycler A* & Shanghai & 5. General Manager \\
\hline Recycler B* & Beijing & 6. General Manager $(* 2$ times) \\
\hline Recycler $C^{*}$ & Fuyang, Zhejiang & 7. General Manager \\
\hline Recycler D* & $\begin{array}{l}\text { Jinan and Shenxian, } \\
\text { Shandong }\end{array}$ & $\begin{array}{ll}\text { 8. } & \text { Founder } \\
\text { 9. } & \text { General Manager }\end{array}$ \\
\hline
\end{tabular}

* Company name kept anonymous by request

Table 4. Composition of the managers group interviewed in Brazil

\begin{tabular}{|c|c|c|}
\hline Company & Location & Managers interviewed \\
\hline Tetra Pak Brazil & São Paulo State & $\begin{array}{l}\text { 1. Environmental Director } \\
\text { 2. Supply Chain Director } \\
\text { 3. Recycling Manager } \\
\text { 4. Business Strategy VP }\end{array}$ \\
\hline $\begin{array}{l}\text { Cooperative A }{ }^{*} \text { (Selective } \\
\text { Collection Cooperative) }\end{array}$ & São Paulo State & $\begin{array}{l}\text { 5. President } \\
\text { 6. Fiscal Counsellor }\end{array}$ \\
\hline Recycler X ${ }^{*}$ & São Paulo State & 7. Manager \\
\hline Recycler $\mathrm{Y}^{*}$ & São Paulo State & 8. Managing Director \\
\hline $\begin{array}{l}\text { Cetesb (Environmental } \\
\text { Government Agency) }\end{array}$ & São Paulo State & 9. General Manager \\
\hline $\begin{array}{l}\text { ABRE (Packaging Sector } \\
\text { Association) }\end{array}$ & São Paulo State & 10. Executive Director \\
\hline
\end{tabular}

* Company name kept anonymous by request 